Europe's Journal of Psychology, 6(3), pp. 34-45

www.ejop.org

\title{
The Relation Between Humor Styles and Empathy
}

\author{
William P. Hampes \\ Black Hawk College \\ Moline, Illinois
}

\section{Abstract}

The Humor Styles Questionnaire and Interpersonal Reactivity Index were given to 103 (28 men, 75 women) undergraduates in a community college in the Midwestern United States. As predicted, significant positive correlations were found between affiliative humor and empathic concern $(r=.23, p<.05)$ and between self-enhancing humor and perspective-taking empathy $(r=.28, p<.01)$. Also, as predicted, there were significant negative correlations between self-enhancing humor and personal distress $(r=-.34, p<$ $.001)$, and between aggressive humor and perspective-taking empathy $(r=-.40, p<$ $.001)$, empathic concern $(r=-.29, p<.01)$ and personal distress $(r=-.20, p<.05)$. Predictions involving self-defeating humor and empathy were not supported. The differences in the correlations for affiliative humor and those of self-enhancing humor were examined in terms of the greater importance of perspective-taking and stress reduction in self-enhancing humor versus affiliative humor, which is more involved with social relationships. The implications for future research were discussed.

Keywords: humor styles; perspective-taking empathy; empathic concern; personal distress.

A number of research studies have indicated that both humor and empathy are associated with satisfying and healthy interpersonal relationships. Empathy is a key component of emotional intelligence, which is associated with satisfying interpersonal relationships (Salovey \& Mayer, 1990; Salovey, Mayer \& Caruso, 2002). Empathy is also associated with the ability to form friendships (Izard, Fine, Schultz, Mostow, Ackerman, \& Younstrom, 2001). It has been found that participants who were accurate in their understanding of their spouses' nonthreatening thoughts and feelings felt closer to their partners than those who were not (Simpson, Orina, \& Ickes, 2003) and men's empathic responding was positively correlated with their feelings of 
intimacy for their partners and women's intimacy was positively correlated with their partners' empathic responding (Mitchell, Castellini, Herrington, Joseph, Doss, \& Snyder, 2008).

Humor has been associated with social competence (Levine \& Zigler, 1976; Masten, 1986; Pelligrini, Masten, Garmezy \& Ferrarese, 1987), intimacy (Mutthaya, 1987; Hampes, 1992, 1994), trust (Hampes, 1999), and satisfying marriages (Ziv, 1988; Rust \& Goldstein, 1989; Ziv \& Gadish, 1989; Laver, Laver, \& Kerr, 1990). This would suggest a possible connection between humor and empathy. Rogers (1980) defined empathy as the ability to understand and experience the thoughts and feelings of another individual. To successfully use and appreciate humor involves a person's ability to shift mentally to different perspectives (Apter, 1982; Wyer \& Collins, 1992), which could be helpful in understanding and experiencing the thoughts and feelings of another person.

It could also be conducive to reducing the stress that inevitably occurs in a close relationship. Kuiper, Martin, \& Olinger (1993) and Kuiper, McKenzie, \& Belanger (1995) found that those high in humor were more likely than those low in humor to perceive potentially threatening events in a positive manner. Other studies have found humor to be a factor in reducing stress (Martin \& Lefcourt, 1983; Lefcourt \& Martin, 1986; Nezu, Nezu, \& Blissett, 1988; Fry, 1995; Newman \& Stone, 1996; Abel, 1998). Individuals who use humor to reduce stress in their relationships should find it easier to focus on another person's thoughts and feelings and thus be more empathic.

Hampes (2001) directly investigated the relationship between humor and empathy and found a positive correlation between the Coping Humor Scale, Situational Humor Response Questionnaire, and Multidimensional Sense of Humor Scale and empathic concern, the extent to which a person feels warmth, compassion, and concern towards others who are having negative experiences (Davis, 1980). However, this study was limited in several respects. First of all, each of the humor tests was a single measure instrument that did not separate humor into maladaptive and adaptive styles. Martin, Puhlik-Doris, Larsen, Gray \& Weir (2003) found four different styles of humor: two adaptive (affiliative and self-enhancing) and two maladaptive (aggressive and self-defeating). The relationship between adaptive styles of humor and empathy could be completely different than the relationship between maladaptive styles of humor and empathy. Secondly, Davis (1980) pointed out that empathy is more than just empathic concern. It can also involve being able to take the perspective of other individuals (perspective-taking empathy), the ability to use one's imagination to transpose oneself into the actions and feelings of fictitious characters in plays, movies, books, and television shows (fantasy empathy), or 
becoming distressed when sensing another person's anxiety or negative feelings (personal distress). The relationship between humor and empathy can be quite different depending on which of the four distinct types of empathy (empathic concern, perspective-taking empathy, fantasy empathy, personal distress) that is being studied. Davis (1983) has developed the Interpersonal Reactivity Index to measure each one of these four types of empathy as separate constructs.

Martin and Dutrizac (2004) studied the relationship between the four styles of humor (affiliative, self-enhancing, aggressive, self-defeating) and empathy. They found that self-enhancing humor was positively correlated with the receiving and giving of empathic responses and aggressive humor was negatively correlated with the giving and receiving of empathic responses. However, this study was limited by the use of a single, global measure of empathy. Therefore, the purpose of the present study is to determine the relationship between the four styles of humor (Martin, et al., 2003) and three types of empathy (Davis, 1980).

Fantasy empathy was not included in this study for a number of reasons. First of all, the research literature does not appear to support a hypothesis concerning the relationship between humor styles and fantasy empathy. Secondly, fantasy empathy doesn't involve the reciprocal interaction between live human beings. Thirdly, it's been pointed out (Baron-Cohen \& Wheelwright, 2004; Spreng, McKinnon, Mar, \& Levine, 2009) that some items on the Fantasy subscale of the Interpersonal Reactivity Index (Davis, 1983), the only scale which measures fantasy empathy, reflect imagination rather than empathy (e.g. "I daydream and fantasize, with some regularity, about things that might happen to me").

According to Martin et al., (2003) affiliative humor is an interpersonal form of humor that involves the use of humor (telling jokes, saying funny things, or witty banter, for example) to put others at ease, amuse others, and to improve relationships. Selfenhancing humor "involves a generally humorous outlook on life, a tendency to be frequently amused by the incongruities of life, and to maintain a humorous perspective even in the face of stress or of adversity" (Martin, et al., 2003, p. 53). Both affiliative and self-enhancing humor are positively correlated with intimacy, extraversion and openness to experience (Martin, et al., 2003; Saraglou \& Scariot, 2002) and both empathic concern and perspective-taking empathy are associated with sensitivity to others and positive interpersonal functioning (Davis, 1983). Therefore, the first hypothesis was that affiliative humor and self-enhancing humor would be positively correlated with empathic concern and perspective-taking empathy, since self-enhancing humor, affiliative humor, empathic concern and perspective-taking empathy are all associated with positive interpersonal 
relationships. Also, since those high in affiliative and self-enhancing humor tend to be high in intimacy, extraversion, and openness to experience and low in anxiety (Martin et al., 2003; Saraglou \& Scariot, 2002) the second hypothesis was that these two styles of humor would be negatively correlated with personal distress, the type of empathy where individuals would be so upset by another person's anxiety and negative feelings that they would psychologically distance themselves from that person.

Aggressive humor is the tendency to use humor to attack or put down other people, and thus involves sarcasm, teasing, ridicule, derision, hostility, or disparagement humor. Those high in this style of humor tend to be high in hostility and low in agreeableness (Martin, et al., 2003; Saraglou \& Scariot, 2002). The third hypothesis is that there would be a negative correlation between aggressive humor and empathic concern, perspective-taking, and personal distress, since these individuals' hostile orientation towards others would seem to preclude empathy for others.

Self-defeating humor "involves excessively self-disparaging humor, attempts to amuse others by doing or saying funny things at one's expense as a means of ingratiating oneself or gaining approval, allowing oneself to be the 'butt' of others' humor, and laughing along with others when being ridiculed or disparaged" (Martin, et al., 2003, p. 54). Those high in this style of humor tend to be high in shyness (Hampes, 2006), Ioneliness (Martin \& Dutrizac, 2004; Hampes, 2005), anxious attachment (Kazarian \& Martin, 2004) and anxiety (Martin, et al., 2003) and low in intimacy and the satisfaction they get from social support (Martin, et al., 2003). Since these individuals tend to have poor interpersonal relationships, the fourth hypothesis was that there would be a negative correlation between self-defeating humor and empathic concern and perspective-taking, which are associated with positive interpersonal functioning (Davis, 1983). Since those high in self-defeating humor tend to be high in anxiety, the fifth hypothesis was that self-defeating humor would be positively correlated with personal distress.

\section{Method}

\section{Participants}

The participants were students ( 28 men and 75 women) at a community college in the Midwestern United States. These students ranged in age from 18 to 56 years ( $M=$ $24.1, \mathrm{SD}=8.1$ ). Students in five psychology classes were asked to participate, and those who volunteered were included in the sample. 
Materials

The Humor Styles Questionnaire has four scales, each of which has eight items. Each item has seven response options in a Likert-type format, anchored by 1 = Totally Disagree and $7=$ Totally Agree. The convergent validity for the Affiliative humor scale was indicated by significant positive correlations with scores on the Miller Social Intimacy Scale and Extraversion on the NEO PI-R. Discriminant validity for the SelfEnhancing humor scale was estimated by a significant negative correlation with scores on Neuroticism on the NEO PI-R, and convergent validity was estimated with significant positive correlations with the Coping Humor Scale and the Humor Coping subscale of the Coping Orientation to Problems Experienced Scale. Convergent validity for the Aggressive humor scale was supported by a significant positive correlation with scores on the Cook-Medley Hostility Scale. Discriminant validity for the Self-Defeating humor scale was based on significant negative correlations with ratings on the Rosenberg Self-Esteem Scale and on the Index of Self-esteem (Martin, et al., 2003). The Cronbach alphas for the current sample were .73, (Affiliative humor), .73 (Self-Enhancing humor), .68 (Aggressive humor) and .75 (Self-Defeating humor).

The Interpersonal Reactivity Index consists of four scales, each scale containing seven items, each item involving five response options presented in a Likert-type format and anchored by "does not describe me well" (1) and "describes me well" (5). The Empathic Concern scale assesses the extent to which a person has feelings of concern, warmth, and compassion for people undergoing negative experiences. The Perspective-Taking scale measures the degree to which a person can adopt and understand the psychological point of view of another person. The Personal Distress scale determines a person's tendency to have feelings of personal anxiety and discomfort in tense interpersonal situations, including situations where others are in distress. The validity for the three scales was established through significant correlations with the Hogan Empathy Scale and The Mehrabian and Epstein Emotional Empathy Scale (Davis, 1983). The Cronbach alphas for the current sample were, .84 (Perspective-Taking), .78 (Empathic Concern) and .81 (Personal Distress).

\section{Results}

Pearson product-moment correlations were calculated between scores on the Interpersonal Reactivity Index and the Humor Styles Questionnaire. Table 1 presents the means and standard deviations for the humor styles and empathy measures in this study, and Table 2 presents the correlations between the four humor styles and those three empathy measures. 
Table 1

Means and Standard Deviations for the Interpersonal Reactivity Index and Humor Styles Questionnaire

Means Standard Deviations

$\begin{array}{lcc}\begin{array}{l}\text { Perspective- Taking } \\ \text { Empathy }\end{array} & 18.87 & 5.33 \\ \text { Empathic Concern } & 21.96 & 4.61 \\ \text { Personal Distress } & 11.41 & 5.63 \\ \text { Affiliative Humor } & 46.45 & 6.55 \\ \text { Self-Enhancing Humor } & 37.27 & 7.40 \\ \text { Aggressive Humor } & 27.67 & 7.67 \\ \text { Self-Defeating Humor } & 26.83 & 8.38\end{array}$

Table 2

Correlations Between the Interpersonal Reactivity Index and Humor Styles

Questionnaire

$\begin{array}{cll}\text { Perspective-Taking } & \text { Empathic } & \text { Personal } \\ \text { Empathy } & \text { Concern } & \text { Distress }\end{array}$

$\begin{array}{lccc}\text { Affiliative } & -.001 & .23^{*} & -.06 \\ \text { Humor } \mathrm{Cl}(.95) & -.201 \text { to.199 } & .03 \text { to.43 } & -.26 \text { to } .16 \\ \text { Self-Enhancing } & .28^{* *} & .18 & -.34^{* * *} \\ \text { Humor } \mathrm{Cl}(.95) & .08 \text { to } .48 & -.02 \text { to } .38 & -.54 \text { to }-.14 \\ \text { Aggressive } & -.40^{* * *} & -.29^{* *} & -.20^{*} \\ \text { Humor Cl (.95) } & -.60 \text { to }-.20 & -.49 \text { to }-.09 & -.40 \text { to } .00 \\ \text { Self-Defeating } & .02 & .16 & .07 \\ \text { Humor } \mathrm{Cl}(.95) & -.18 \text { to } .22 & -.04 \text { to } .36 & -.13 \text { to } .27\end{array}$

$* \quad \mathrm{p}<.05 * * \quad \mathrm{p}<.01$ *** $\mathrm{p}<.001$.

Affiliative humor and empathic concern $(r=.23, \mathrm{p}<.05)$ and self-enhancing humor and perspective-taking empathy $(r=.28, p<.01)$ were significantly and positively correlated, partially supporting the first hypothesis. Self-enhancing humor was significantly and negatively correlated with personal distress ( $r=-.34, p<.001$ ), partially supporting the second hypothesis. The third hypothesis was supported by 
the significant and negative correlations between aggressive humor and perspective-taking empathy $(r=-.40, p<.001)$, empathic concern $(r=-.29, p<.01)$, and personal distress $(r=-.20, p<.05)$. The fourth and fifth hypotheses involving selfdefeating humor and empathic concern, perspective-taking, and personal distress were not supported.

\section{Discussion}

According to Martin, et al., (2003) conceptually one of the qualities that separates affiliative humor from self-enhancing humor is the ability of those high in the latter to use humor as a way to change one's perspective. By using self-enhancing humor to change one's perspective when threatened a person can better reduce stress in these situations. Self-enhancing humor was developed to measure the use of humor to reduce stress and therefore it has higher positive correlations with measures of the use of humor in stressful situations than does affiliative humor (Martin et al, 2003). This is consistent with the present findings that self-enhancing humor had a significant. positive correlation with perspective-taking empathy and a negative correlation with personal distress whereas affiliative humor did not.

On the other hand affiliative humor is positively correlated with measures of coping humor (Martin et al, 2003). In that respect it is surprising that affiliative humor is not also significantly negatively correlated with personal distress. After all, low levels of personal distress would seem to be compatible with high levels of empathic concern, since personal distress would seemingly hinder the empathic concern with which affiliative humor is positively correlated.

In this respect it is interesting that a factor analytic study done by Cliffordson (2001) found that empathic concern was more central to a single general empathic dimension than personal distress. Baron-Cohen and Wheelright (2004) and Spreng et al. (2009) have pointed out that the Personal Distress scale largely measures discomfort, anxiety, and fear of losing control in threatening situations in general, rather than simply being distressed in interpersonal situations. In fact, some of the items on the Personal Distress subscale ("In emergency situations, I feel apprehensive and ill at ease", "Being in a tense emotional situation scares me") don't mention other people at all. This is important because someone could act quite differently in stressful situations that involve other people's distress than those that don't. One way of teasing out these differences would be to use a controlled study in which participants of varying levels of affiliative humor were exposed to a situation that involved another person who was in distress to see if there would be significant 
differences in empathic concern between those high and those low in affiliative humor in that situation.

Martin et al's (2003) characterization of affiliative humor as an adaptive interpersonal style of humor and self-enhancing humor as an adaptive intrapersonal style of humor is consistent with the difference in the correlations between affiliative humor and self-enhancing humor with empathic concern. Those who are more interpersonally oriented are seemingly more likely to show concern, warmth, and compassions for others than those who are more intrapersonally oriented.

That the correlation between affiliative humor and empathic concern was stronger than between self-enhancing humor and empathic concern is also consistent with Davis (1983), who found that of the two types of empathy, empathic concern is a more "emotional" measure of empathy and perspective-taking empathy the more "cognitive" type of empathy. Therefore, the interpersonal affiliative humor would seemingly be more strongly related to the "emotional" empathic concern than would self-enhancing humor, just as the more intrapersonal self-enhancing humor seemingly would be more strongly related to the "cognitive" perspective-taking empathy than would affiliative humor.

Empathy enables a person to experience the psychological pain of the target of aggressive humor, making that person less likely to use aggressive humor in order to avoid the experience of pain for both individuals. Therefore, those who use aggressive humor would tend to be low in empathy. This is supported by the significant negative correlations between aggressive humor and three of the types of empathy. This would suggest that those who use aggressive humor not only don't want to help someone who's feeling badly, but have difficulty experiencing both emotionally and cognitively the person's negative feelings. The especially strong correlation between aggressive humor and perspective-taking empathy is particularly interesting in this respect. It's hard to imagine how someone who has trouble understanding another person's perspective would feel sympathy or distress at another person's plight, something consistent with the negative correlations between aggressive humor and empathic concern and personal distress. Those who use aggressive humor on a regular basis may set up a vicious cycle in which the targets of this style of humor withdraw from those who use it, which makes it even harder for those who use aggressive humor to get closer to other people, which in turn makes it harder for them to develop empathy.

The positive correlations, albeit nonsignificant correlations, between self-defeating humor and the three types of empathy seem to indicate that there are other 
reasons why these individuals have such difficulties with intimacy and close relationships besides lack of empathy. Individuals high in self-defeating humor tend to be low in self-esteem (Martin, et al., 2003) as well as high in anxiety (Martin, et al., 2003) and shyness (Hampes, 2006). These characteristics, more than the lack of empathy, may be responsible for their poor interpersonal relationships (Martin, et al., 2003; Kazarian and Martin, 2004, Martin \& Dutrizac, 2004; Hampes, 2005).

More needs to be done to study the causal relationship between the styles of humor and types of empathy. The significant correlations found in this study between particular styles of humor and particular types of empathy do not reveal whether the style of humor causes the type of empathy, the type of empathy causes the style of humor, or a third variable causes both. A study could be done to investigate whether changing particular types of empathy would affect particular styles of humor, or to see whether changing styles of humor would affect the different types of empathy.

In future studies it would also be interesting to investigate the relationship between the different styles of humor and the types of empathy, on the one hand, and cognitive variables such as wisdom and interpersonal variables such as generativity, on the other, to see if these variables would be differentially correlated with the different humor styles and different types of empathy. For example, it could be studied whether those high in affiliative humor and empathic concern are also high in generativity, which involves providing for the welfare of others, or whether those high in self-enhancing humor and perspective-taking empathy are also high in wisdom.

\section{References}

Abel, M.H. (1998). Interaction of humor and gender in moderating relationships between stress and outcomes. The Journal of Psychology. 132, 267-274.

Apter, M.J. (1982). The experience of motivation: the theory of psychological reversals. London: Academic Press.

Baron-Cohen, S. \& Wheelwright, S. (2004). The empathy quotient: An investigation of adults with Asperger syndrome or high functioning autism, and normal sex differences. Journal of Autism and Developmental Disorders, 34, 163-175.

Cliffordson, C. (2001). Parents' judgments and students' self-judgments of empathy. European Journal of Psychological Assessment, 17, 36-47. 
Davis, M. H. (1980) A multidimensional approach to individual differences. Catalog of Selected Documents in Psychology, 10, 85.

Davis, M.H. (1983). Measuring individual differences in empathy: Evidence for a multidimensional approach. Journal of Personality and Social Psychology, 44, 113-124.

Fry, P.S. (1995). Perfectionism, humor and optimism as moderators of health outcomes and determinants of coping styles of women executives. Genetic, Social, and General Psychology Monographs, 12, 211-245.

Hampes, W. P. (1992). Relation between intimacy and humor. Psychological Reports, 71 , 127-130.

Hampes, W. P. (1994). Relation between intimacy and the Multidimensional Sense of Humor Scale. Psychological Reports, 74, 1360-1362.

Hampes, W.P. (1999). The relationship between humor and trust. Humor: International Journal of Humor Research, 12, 253-259.

Hampes, W.P. (2001). Relation between humor and empathic concern. Psychological Reports, 88, 241-244.

Hampes, W.P. (2005). Correlations between humor styles and loneliness. Psychological Reports, 96, 747-750.

Hampes, W.P. (2006). Humor and shyness: The relation between humor styles and shyness. Humor: International Journal of Humor Research, 19, 179-187.

Izard, C., Fine, S., Schultz, D., Mostow, A., Ackerman, B., \& Younstrom, E. (2001). Emotion knowledge as a predictor of social behavior and academic competence in children at risk. Psychological Science, 12, 18-23.

Kazarian, S.S. \& Martin, R. A. (2004). Humor styles, personality, and well - being among Lebanese university students. European Journal of Personality, 18, 209-219.

Kuiper, N.A., Martin, R.A., \& Olinger, L.J. (1993). Coping humour, stress, and cognitive appraisals. Canadian Journal of Behavioural Science, 25, 81-96.

Kuiper, N.A., McKenzie, S.D., \& Belanger, K.A. (1995). Cognitive appraisals and individual differences in sense of humor: Motivational and affective implications. Personality \& Individual Differences, 19, 359-372. 
Laver, R H., Laver, J. C. \& Kerr, S.T. (1990). The long-term marriage: Perceptions of stability and satisfaction. International Journal of Aging \& Human Development, 31 , 189-195.

Lefcourt, H. M. \& Martin, R.A. (1986) Humor and life stress. New York: Springer-Verlag.

Levine, J., \& Zigler, E. (1976). Humor responses of high and low premorbid competence alcoholic and nonalcoholic patients. Addictive Behaviors, 1, 139-149.

Martin, R.A. \& Dutrizac, G. (2004) Humor styles, social skills, and quality of interactions with close others: a prospective daily diary study. Paper presented at the annual conference of the International Society for Humor Studies, Dijon, France.

Martin, R.A. \& Lefcourt, H.M. (1983). Sense of humor as a moderator of the relation between stressors and moods. Journal of Personality and Social Psychology, 45, 13131324.

Martin, R.A., Puhlik-Doris, P., Larsen, G., Gray, J., \& Weir, K. (2003).Individual differences in uses of humor and their relation to psychological well-being: development of the Humor Styles Questionnaire. Journal of Research in Personality, 37, 48-75.

Masten, A S. (1986). Humor and competence in school-aged children. Child Development, 57, 461-473.

Mitchell, A.E., Castellini, A.M., Herrington, R. L., Joseph, J.I., Doss, B.D., \& Snyder, D.K. (2008). Predictors of intimacy in couples' discussions of relationship injuries: An observational study. Journal of Family Psychology, 22, 21-29.

Mutthaya, B.C. (1987). Relationship between humor and interpersonal orientations Journal of Psychological Research, 31, 48-54.

Newman, M.G. \& Stone, A. A. (1996). Does humor moderate the effects of experimentally induced stress? Annals of Behavioral Medicine, 18, 101-109.

Nezu, A.M., Nezu, C.M., Blissett, S.E. (1988). Sense of humor as a moderator of the relation between stressful events and psychological distress: A prospective analysis. Journal of Personality and Social Psychology, 54, 520-525.

Pellegrini, D. S., Masten, A.S., Garmezy, N. \& Ferrarese, J.(1987). Correlates of social and academic competence in middle childhood. Journal of Child Psychology \& Psychiatry \& Allied Disciplines, 28, 699-714.

Rogers, C.R. (1980) A way of being. Boston, MA: Houghton-Mifflin 
Rust, J., \& Goldstein, J. (1989). Humor in marital adjustment. Humor: International Journal of Humor Research, 2, 217-223.

Salovey, P., \& Mayer, J.D. (1990). Emotional intelligence. Imagination, Cognition, and Personality, 9, 185-211

Salovey, P., Mayer, J.D., \& Caruso, D. (2002) The positive psychology of emotional intelligence. In C. R. Snyder \& S. J. Lopez (Eds.), Handbook of positive psychology. New York: Oxford.

Saraglou, V. \& Scariot, C. (2002). Humor Styles Questionnaire: Personality and educational correlates in Belgian high school and college students, European Journal of Personality, 16, 43-54.

Simpson, J.A., Orina, M. M., \& Ickes, W. (2003). When accuracy hurts, and when it helps: A test of the empathic accuracy model in marital interactions. Journal of Personality and Social Psychology, 85, 888-893.

Spreng, R. N., McKinnon, M. C., Mar, R. A., \& Levine, B. (2009). The Toronto Empathy Questionnaire: Scale development and initial validation of a factor-analytic solution to multiple empathy measures. Journal of Personality Assessment, 9, 62-71.

Wyer, R.S. \& Collins, J.E. (1992). A theory of humor elicitation. Psychological Review, 99, 663-688.

Ziv, A. (1988). Humor's role in married life. Humor: International Journal of Humor Research, 1, 223-229.

Ziv, A. \& Gadish, O. (1989). Humor and marital satisfaction. Journal of Social Psychology, $129,759-768$.

About the author:

William Hampes has been a Professor of Psychology for over 30 years. Currently he is in the Department of Social, Behavioral and Educational Studies at Black Hawk College. He has published a number of papers in the area of humor and personality, including the relationship between humor and such variables as extraversion, intimacy, generativity, trust, empathy, loneliness and shyness.

Address for correspondence: William Hampes, Department of Social, Behavioral, and Educational Studies, Black Hawk College, 6600 34th Avenue, Moline, Illinois 61265 (email: hampesw@bhc.edu; Fax: 1-309-796-5976). 